\title{
VOCES JURÍDICAS DISÍMILES \\ Y DISCURSO POLÍTICO MONÁRQUICO, \\ EL CASO DE PARTIDAS Y SU EDICIÓN DE 1555
}

\author{
Daniel Panateri \\ Universidad de Buenos Aires \\ IMHICIHU-CONICET \\ danielpanateri@gmail.com
}

\begin{abstract}
Resumen
El artículo estudia los modos de funcionamiento políticos de los elementos jurídicos implicados en el texto alfonsí Las Siete Partidas (en este caso, uso, costumbre y fuero). El espacio donde se analizan es tanto el siglo XIII como el siglo XVI a partir de su edición de 1555 a cargo de Gregorio López. La propuesta implica entender el texto jurídico de Partidas como un elemento recurrente en los momentos de crisis política monárquica castellana en tanto marco de acción y legitimación del poder regio. Por este motivo, nuestro planteamiento conlleva dos contextos disímiles, pues el centro está en los cambios semánticos operados sobre el texto de Partidas en el siglo XVI, de allí que sea central entender el punto de partida.
\end{abstract}

\section{Palabras clave}

Política, derecho, Alfonso X, Castilla.

\begin{abstract}
The aim of this paper is to study the ways in which the juridical text Siete Partidas establishes a relationship between political concepts and legal issues, specifically the notions of uso (usage), costumbre (custom) and fuero (privilege). We will analyse both the thirteenth-century text and the edition of 1555 by Gregorio López. In our view, the Partidas stands as a recurrent element in Castile in different contexts of monarchical crisis, which has been repeatedly functioning as a frame for action and royal legitimation. We will focus on two different contexts, those of the thirteenth and sixteenth centuries, in order to study the semantic changes brought about to the text of the sixteenth-century printed version of the Partidas.
\end{abstract}

\section{Keywords}

Politics, law, Alfonso X, Castile. 


\section{INTRODUCCIÓN}

La propuesta de este trabajo es analizar la introducción de las diversas voces jurídicas dentro del texto Las Siete Partidas con la intención de entender la operación política detrás de dicho procedimiento. Partimos de pensar, en consonancia con Rodríguez Velasco (2010), que Partidas fue más que un contenido un escenario de conflicto que permitía, en cada nueva puesta por escrito, revitalizar el lugar político de la monarquía. En tal sentido, comenzamos mostrando la manera probable de funcionamiento de este texto en el siglo xirm para luego llegar a su utilización en un contexto político diverso, el de I555. En ese momento, frente a la debilidad concreta del cuerpo de Carlos I, Partidas desempeńó un papel crucial al fortalecer el cuerpo regio que se estaba transfiriendo. A partir de estas diferencias veremos cómo el nuevo contexto hizo operar los conceptos políticos del texto jurídico partiendo del trabajo de la glosa del editor y el empleo del concepto "relocación de sentidos".

La transmisión del texto de Partidas a lo largo de la historia no puede precisarse de manera lineal. ${ }^{\mathrm{I}}$ Asimismo, a diferencia de la mayoría de las tradiciones manuscritas que tampoco suelen ser fáciles de asir, este camino complejo y quebrado nos sume, en el estado actual del conocimiento, en la imposibilidad de determinar de manera exacta cuál es la manera en la que se relacionan las versiones conservadas de la Primera Partida. Esta sección ha sido particularmente modificada a lo largo del tiempo, teniendo en cuenta que se supone como probable la existencia en algún momento entre 1256 y 1272 de un solo texto que pudo circular como Partidas y que sintetizó algunas de las más renovadoras ideas políticas sobre la monarquía emergente del siglo XIII castellano. Este problema llevado hasta el límite sugiere que ni siquiera podemos estar seguros de la propia existencia en tiempos de Alfonso X de un texto denominado Las Siete Partidas. ${ }^{2}$

I García Gallo (I95I-I952), Arias Bonet (I975), MacDonald (I979), Craddock (I98I), entre otros.

${ }^{2}$ García Gallo (1976) ha llegado a establecer esta hipótesis de la inexistencia de una obra denominada Las Siete Partidas en época de Alfonso X. Sostiene que lo que conocemos hoy por tal obra es, en realidad, producto de un taller denominado con el nombre de alfonsí, pero que habría trabajado entre el último tercio del siglo XIII y principios del XIV. El gran problema de esta intuición es, justamente, la falta de hechos que la correspondan. En este sentido, las críticas de Craddock (I98I) han sido devastadoras y, hasta el momento, nadie ha revitalizado esas hipótesis sin sostén. Esto último, sin embargo, no elimina el problema de la cronología y lo complejo de su determinación, como deja, a su vez, bien claro Craddock. En este sentido, en vistas de la imposibilidad material en la que estamos sumidos para dar una respuesta determinante a estos interrogantes, vamos a plegarnos a la 
En rigor, debemos comenzar aceptando y considerando dos problemas importantes que resultan enigmas y, a la vez, preguntas constitutivas para nuestro estudio: ¿qué versión circuló originalmente como Las Siete Partidas? y ¿a qué responde la existencia de dos textos sensiblemente disímiles que son asimismo llamados indistintamente de un modo igual?

$\mathrm{Al}$ menos desde el siglo XIV circulaban manuscritos, no solo con las variantes sino también con distintas versiones de la Primera Partida, bajo el único nombre de Las Siete Partidas (García Gallo, I95I-52, p. 380). ${ }^{3}$ Estas versiones y variantes no se limitaban a contener las dos que, podríamos decir, son opuestos arquetípicos entre sí (manuscrito silense y manuscrito londinense), ${ }^{4}$ sino que además se sumaban versiones refundidas que tomaban partes y creaban un nuevo texto. Ninguna de las dos ediciones modernas de la obra ha logrado reparar esta situación. ${ }^{6}$ Por el contrario, dichas "ediciones" han sido intentos de estabilizar el texto multiplicado, ajenas a las técnicas filológicas actuales y contribuidoras del proceso de multiplicación semántica.

A estas complicaciones podemos sumar muchas más. Por ejemplo, la profusión de textos refundidos en época de Alfonso XI y su preparación del Ordenamiento de Alcalá en 1348 . La producción de manuscritos de Partidas resulta notable para esta época, pero, una vez más, no poseemos elementos empíricos para sostener que esta estabilización se diera por medio de un contenido nuevo no presente ya en la tradición del siglo XIII. Hay que reconocer, igualmente, que no hay datos de la versión sapiencial antes de la inclusión de la obra del rey Sabio

mayoría de la crítica y a darle la entidad histórica necesaria a Partidas tal y como la ha tenido desde los últimos setecientos años para dar curso a su estudio.

${ }^{3}$ Las versiones a las que hacemos referencia son las denominadas "legalista" y "sapiencial". La primera, asociada a una redacción temprana posee un fuerte carácter impositivo en su composición, mientras que la segunda, de posterior recensión, se distingue por una ilación argumental más fluida y dedicada al convencimiento más que más que al acatamiento prescriptivo. Al respecto, Arias Bonet (1975), Craddock (I98I), entre otros.

${ }^{4}$ Nos referimos a los MS. Espagnol 440 de la Bibliothéque Nationale, París (BETA manid III3) y Ms. Add. 20.787, British Museum, Londres (BETA manid III2).

5 Sin lugar a dudas la principal refundición fue la contenida en el denominado manuscrito neoyorkino (Ms. HC 397/573, Hispanic Society of America, New York, BETA manid I039). Allí, aparece claramente un intento de acoplar y unificar dos versiones. Esto se corrobora por la implementación inacabada, los espacios en blanco y la redacción quebrada de las leyes compartidas. Arias Bonet (1972) lo da a conocer en un pequeńo artículo ecdótico, pero todavía se espera un trabajo completo sobre el mismo.

${ }^{6}$ Montalvo y López. Dejamos de lado a Arias Bonet ya que solo transcribe el ms. londinense. Asimismo, dejamos de lado la de Academia, pues nos centramos en el período moderno. De cualquier modo, véase las críticas de Arias Bonet y García Gallo, especialmente a esta última edición. 
en el ordenamiento del nieto ya que el manuscrito silense debe ser datado en la primera mitad del siglo xIV sin mayores especificaciones. Esta precisión aparece posibilitada en Faulhaber et al (2011) ${ }^{7}$ y además es la conclusión a la que llegamos en Panateri (2015) por medio de un estudio paleográfico del manuscrito, en el que se cuestionó la datación más temprana que fue propuesta por Arias Bonet (1970). La falta de pruebas no permite probar ausencias (ad ignorantiam). Por lo tanto, sin la necesidad de incurrir en ceteris paribus, sostenemos que en el estado actual de nuestro conocimiento tenemos dos opciones: cerrar toda posibilidad de análisis de la obra hasta que alguien realice un cotejo completo de todos los manuscritos y las ediciones (que implicaría, necesariamente, encontrar los manuscritos extraviados); o entender este problema como un elemento constituyente y con el cual hay que lidiar y trabajar a su pesar. ${ }^{8}$ Naturalmente, nuestra posición es la segunda.

A partir de dicha posición, que es teórica, se desprende que el análisis sobre la obra de Gregorio López es un análisis sobre la propia obra alfonsí, en el sentido de que con seguridad constituye un reflejo de su supervivencia en el tiempo y de uno de sus estadios particulares, ya que el texto propuesto por López contribuye a profundizar el proceso de reproducción de Partidas. Actualmente, dicha edición es la más reputada para los historiadores del derecho. Aunque poco nos diga sobre el siglo XIII y quizá sea decididamente un error (por lo menos para la selección que mencionamos) basar estudios sobre lo que Alfonso X pudo decir a partir de esta edición, sí es cierto que el producto del trabajo de Gregorio López nos presentará una serie de elementos explicativos sobre la propia sociedad que la produjo. Más allá de esto último, que es en alguna medida autoevidente, resulta de central interés que la edición de López es un estadio del paso de Partidas en el tiempo. De ahí su relevancia y la necesidad de entender la propia naturaleza y función que habría cumplido dicha edición (su intención, objetivos, etc.) en los años finales del reinado de Carlos I. De este modo, no esperamos que el texto meramente nos hable del contexto sino que pretendemos estudiar un estadio cronológico de un texto que se ha encontrado en constante pervivencia y que ha ayudado, en tanto discurso de poder, a moldear su contexto de manera dialéctica.

7 Dicha datación fue realizada por Morel-Fatio. Vid supra nota 4.

${ }^{8} \mathrm{Si}$ bien es necesario aclarar que la mayoría de las variantes y la propia existencia de versiones muy distintas se producen en la I $P$, desde el prólogo hasta el título IV, el resto de la obra no escapa al problema de lagunas, huecos e incapacidad de fijar como verdadero de época alfonsí lo conservado. Véase García Gallo (1951-1952 y 1984), y más reciente Rodríguez Velasco (2010). 
En una primera lectura, podemos apreciar que en el título II de la Primera Partida parecería haber una disociación entre las consideraciones sobre la ley y las otras expresiones jurídicas (en especial la 'costumbre'). Esta hipótesis parecería tener sentido al ver que en la primera redacción de Partidas, i. e. la contenida en el ms. londinense, la postura sostenida en la definición de ley se mostraba menos sensible al concepto romano de rex legibus solutus est. Allí encontramos, de ese modo, una obligación vinculante para el rey en cuanto a obedecer las leyes. Pero, a su vez, esa redacción evitaba, al igual que el texto del Espéculo, toda mención sobre la costumbre. Allí, el título II ya incorporaba la materia eclesiástica, haciendo desaparecer toda regulación sobre esas otras expresiones jurídicas. Las redacciones posteriores, contenidas en varios manuscritos de la versión sapiencial, radicalizan la teoría política del rey por encima de la ley estableciendo que aunque sea bueno que la cumpla, no se encuentra ya obligado a hacerlo (Craddock, 1983). Sin embargo, todos los testimonios que conservan esta versión contienen un título II dedicado al 'uso', la 'costumbre' y el 'fuero'. Esto nos lleva a deducir que mientras la capacidad real de Alfonso X de imponer sus ideas disminuía, su teoría política se radicalizaba. Además, esto último se producía de la mano de incorporar esos contenidos radicales por medio del registro sapiencial y no ya del legalista-impositivo que denota el manuscrito londinense. Finalmente, debemos postular que el hecho de que se encuentren esas expresiones jurídicas relacionadas con la 'costumbre' en la segunda recensión constituye un síntoma claro del fracaso alfonsí frente a los poderes territoriales declarados en su contra en Lerma en I272. Con este panorama nos damos por tanto a la comprobación textual.

Las expresiones jurídicas ancladas en la creación de derecho local aparecen en el título II de los manuscritos de Partidas que muestran una segunda o tercera recensión (con la excepción del manuscrito neoyorkino y del zabalburense'). Debemos ver, por tanto, la manera sutil en la que funciona discursivamente la inserción de estas expresiones jurídicas, que otorgan y a la vez limitan todo aquello que fue arrancado a la monarquía desde 1272.

Partida I, título II, ley I plantea ya elementos confusos, contradiciendo el espíritu de la ley 13 del título anterior, donde se dejaba asentado el deseo de claridad del derecho para su mejor entendimiento. Así, explica que el 'uso' "es cosa que

9 El zabalburense es un vestigio de la versión legalista. MS Vitrina X-I3I de la Biblioteca Francisco de Zabálburu y Basabe, Madrid (BETA manid IIO5). 
nace de aquellas cosas que hombre dize e faze e sigue continuadamente por gran tiempo e sin embargo ninguno" ${ }^{\text {IO }}$. Esta definición resulta tan vaga y oscura que resulta imposible determinar la constitución del 'uso' a partir de lo expuesto. Hay mención al acto, al factor temporal y a la ausencia de coacción. No se especifica qué tipos de actos sirven como 'uso' (ya que es evidente que no todo acto puede llegar a constituir derecho) ni cuánto tiempo implica ni tampoco cómo puede entenderse la relación entre la coacción y los 'usos' derivados, por ejemplo, de una orden emitida por una autoridad. Consideramos que en esta indefinición reside la capacidad de acción del tribunal, más concretamente del juez. La segunda ley introduce otro elemento más, que es claramente constitutivo, pero lo aleja de la primera definición. Este es la publicidad del acto. Sostiene que para darle status normativo el 'uso' debe ser visto por las personas de derecho, los jueces. En este sentido, el texto vuelve a "enredarse" pues, si el juez debe conocer el acto, significa que su existencia previa es irrelevante antes del reconocimiento judicial. Por lo tanto, si el uso requiere de "gran tiempo" y continuado ¿en qué momento puede empezar a "correr el reloj" y asentarse el status requerido?

Posteriormente explica las condiciones que debe poseer este 'uso' para su reconocimiento jurídico. Enuncia cinco que en realidad se reducen a tres. Las dos primeras redundan sobre lo mismo y proponen que sean buenos y que no generen daño. La cuarta, de significativa importancia, limita el 'uso' a los derechos establecidos. La quinta, condiciona la posibilidad de existencia del 'uso' a que lo ordene el señor territorial o que lo quiera la mayoría de los locales, pero consintiendo luego dicho señor ${ }^{\text {II }}$. En la ley citada puede verse una contradicción con respecto al prólogo del título. Este que decía que el uso "embarga” la ley, pero

Io De aquí en más, excepto previa aclaración, usaremos para todas las citas de carácter sapiencial la edición de López. La razón de esto es que la accesibilidad a dicha edición la hace preferible para la constatación por parte del lector de los pasajes escogidos. Asimismo, claro está, reproducimos López siempre y cuando el pasaje se corresponda con el ms. de la versión mentada. Si hubiera variantes significativas, se optará y se explicitarán las razones de la elección.

II "Las razones porque el uso gana tiempo son en cinco maneras. La primera, si se faze de cosa que puede venir bien e no mal, asi como ya diximos. La segunda, que sea fecho paladinamente e con gran consejo. La tercera, que aquellos que del usan, que lo fagan a buen entendimiento e con plazer de aquellos en cuyo poder son o de otros sobre que ellos an poder. La quarta, si non va contra derechos establecidos non seyendo primeramente tollidos. La quinta, si se faze por mandado del señor que a poder sobre ellos o de acuerdo que el los ayan entresi, entendiendo que viene ende gran pro luego consinstiendolo el seńor y plaziendole, e este tiempo que gana es en dos maneras. La primera es en tiempo pequeño non podiendo el uso escusar. La segunda en tiempo grande segund la bondad del uso e por todas estas razones puede ganar tiempo segund la manera del uso e si ansi non fuese fecho, poder lo yan perder" (P. I, II, 3). 
¿cómo el derecho establecido puede condicionar entonces al uso? Una respuesta posible sería el tiempo, pero al estar indefinido la letra jurídica sigue dejando el proceso abierto para la decisión del juez o la ambigüedad lisa y llana ${ }^{\mathrm{I}}$.

La ley cuarta comienza con la costumbre y ya le propone otro status al considerarla derecho. La define, en realidad, como "derecho o fuero". Esto último remite a una diferencia que no termina de ser zanjada en el discurso jurídico medieval castellano. Derecho, en principio, sería asociado a aquello que es producido por la ley (que es escrita), mientras que fuero sería aquello que es "como derecho", pero no escrito. Sin embargo, el nombre con el que se conoció la primera redacción de Partidas fue "El fuero del libro de las leyes" ${ }^{\text {"13 }}$. La voz 'fuero', que Alfonso X definirá como aquello que implica publicidad de la norma (por el lugar, el forum donde se leía), se terminó asociando a una instancia normativa equiparada a la ley pero no siendo su soporte escrito. De cualquier modo, al poner a la costumbre en ese lugar, la está equiparando en su potencia efectiva, o en la vinculación de su observancia, a la ley. Pero esto no implica que sean necesariamente lo mismo desde otras perspectivas. Una primera diferencia estará en el plano de la factura de esa expresión jurídica. Dicha descripción del proceso puede mostrar una diferencia significativa con la ley. La definición, en consecuencia, de este elemento jurídico vuelve a poner al tiempo en primer plano. Alfonso establece que esto es "algo" que

usaron los omes luengo tiempo ayudandose de el en las cosas e en las razones sobre que lo usaron. E son tres maneras de costumbre. La primera es aquella que es sobre alguna cosa señaladamente, asi como en logar o en persona cierta. La segunda, sobre todo tambien en personas como en logares. La tercera, sobre otros fechos señalados que fazen los omes de que se hallan bien en que estan firmes $(P$. I, II, 4).

Esta indeterminación de la escritura sumada a la ausencia de estructuras argumentativas no hace menos que llamar la atención. Solo hay una parataxis que se señala y se desarrolla. No se encuentra ninguno de los elementos cohesivos tra-

${ }^{\text {I2 }}$ Esto resulta del siguiente hecho que sacamos de la ley en cuestión. El 'uso' no puede ir contra el derecho establecido, excepto que dicho derecho haya sido derogado. Una vez que el derecho haya sido derogado, el 'uso' puede funcionar; pero nada indica que sea el 'uso' el que generara esa derogación. Aun siendo causa para la derogación, no es el reconocimiento jurídico del 'uso' el que genera ipso facto que el derecho deje de funcionar sino otros mecanismos que se encuentran en la esfera de la tarea legislativa monárquica. Por lo tanto, el 'uso' por sí solo no deroga el derecho establecido. Así, plantea una contradicción o negación de aquello que planteó al principio en el prólogo del título.

${ }^{13}$ "Este es el prologo del libro del fuero de las leyes que fiço el noble don Alfonso". Así comienza el texto del ms. londinense en Ir.a (vid supra nota 4 ). 
dicionales del discurso alfonsí, que fueron descriptos y sistematizados por Cano Aguilar (1996) y Lacomba (2004) y que están presentes a lo largo de toda la obra. Aquí, su ausencia y la diametral pobreza de la escritura son notables. La primera manera y la segunda son, esencialmente, la misma. La tercera es un conjunto absolutamente indeterminado y vacío de definición jurídica.

En la ley quinta, que condiciona al creador, aparece el impreciso "pueblo", tal y como ya mencionamos más arriba. ${ }^{14}$ Aparece el elemento temporal mejor definido ya que designa diez o veinte años como condición constitutiva de la costumbre. A su vez, resulta interesante que no vuelva sobre el concepto de uso. El texto allí plantea que si "el pueblo" hace "alguna cosa" por ese período de tiempo "como en manera de costumbre" será válida dicha expresión jurídica. Esta nueva indeterminación de los elementos que componen la consuetudo nos permite dudar de la utilidad de la inclusión del 'uso' en las leyes anteriores. Seguidamente, el texto vuelve a colocar más obstáculos en el camino. Así, propone un énfasis en las condiciones que inhabilitan el reconocimiento de la costumbre más que la definición de aquello que sí la posibilita. De tal modo, debe saberlo el señor del lugar, debe consentirlo y no contradecirlo. Inmediatamente después el texto solicita que se establezcan al menos dos sentencias "en este mismo tiempo" para darle verdadero curso a la consuetudo y, a su vez, que nadie la contradiga en el proceso en ningún aspecto. Asimismo, debe poseer razón (entiéndase ratio). Una pregunta razonable sería: ¿cómo podría ese "indeterminado pueblo" conseguir cumplimentar los requisitos de "ciencia” y "razón” para elaborar sus costumbres? La respuesta indica que debemos pensar necesariamente una vez más en los profesionales del derecho dentro de la elaboración de esta "norma popular". Asi-

${ }^{14}$ "Pueblo tanto quiere dezir como ayuntamiento de gentes de todas maneras de aquella tierra do se allegan. E desto no sale ome, ni muger, ni clerigo, ni lego. E tal pueblo como este, o la mayor partida del, si usaren diez o veynte ańos a fazer alguna cosa, como en manera de costumbre sabiendolo el señor de la tierra e no lo contradiziendo e teniendolo por bien, pueden la fazer e deve ser tenida e guardada por costumbre si en este mismo tiempo fueren dados concegeramente dos juyzios por ella de omes sabidores e entendidos de juzgar, e no aviendo quien gelas contralle, eso mismo seria quando contra tal costumbre en el tiempo sobredicho alguno pusiese su demanda o su querella o dixiese que non hera costumbre que deviese valer. E el juzgador ante quien acaeciese tal contienda, oydas razones de ambas las partes, juzgase que era costumbre de todo en todo non cabiendo razones de aquellos que lo contra dixesen. E otrosi dezimos que la costumbre que el pueblo quiere poner e usar de ella deve ser con derecha razon e non contra la ley de Dios ni contra seńorio ni contra derecho natural ni contra procomunal de toda la tierra del logar do se faze, e deve la poner con gran consejo e non por yerro ni por antojo ni por ninguna otra cosa que les mueva sino derecho e razon e pro. Ca asi de otra guisa las pusieren non seria buena costumbre mas dańamiento de ellos e de toda justicia" (P. I, II, 5). 
mismo, no puede contrariar a la ley de Dios, ni a la del seńorío donde intentase plasmarse y tampoco debe contravenir el derecho natural, ni el "pro comunal" y, también, debe ser con "gran consejo". Evidentemente, los medios para establecer costumbre eran tan indeterminados como complejos.

La ley que sigue $(P$. I, III, 6) define y limita a la costumbre en cuanto a su campo de acción. ${ }^{\mathrm{I}} \mathrm{El}$ argumento central en torno a la fuerza legal que posee la costumbre se construye por medio de una sutil contraposición. En este caso, el uso de la conjunción "ca" marca un enlace lógico, como casi siempre en la ilación sintáctica alfonsí, pero no por medio de la estructura usual de causas en parataxis y "remate" final. Esta inclusión parece un tanto apresurada y denota el intento de focalizar una contraposición o aclaración: que toda la fuerza de la costumbre se aplica especialmente, o únicamente, para contiendas entre particulares cuando no sea materia regulada por "leyes escritas". El primer mojón argumentativo se plantea con el "otrosi”. Esta partícula aditiva vuelve, en realidad, sobre el elemento anterior y plantea que cuando haya leyes sobre la materia en tratamiento, la costumbre tome la forma de una "interpretación" de dicha ley para formarse. Es decir que, si bien adiciona información stricto sensu, la estructura argumentativa lo hace recalcando la primera intervención que "solicita" la observancia sobre la ley (en este caso, para hacer costumbre). De esto podría derivar una consideración contraria a lo expuesto en Espéculo y en la primera redacción de Partidas, ya que habilitar una interpretatio particular de la ley y darle nueva forma con carácter de aplicación local permite la tan combatida multiplicidad del derecho. Sin embargo, esto es permitido por vía de la ratio que se conserva. Así, esa forma de consuetudo, en realidad, no es más que lo que la ley decía en su esencia. Un elemento que ayuda, de cualquier modo, a morigerar esta multiplicidad es el

Is "Fuerça muy grande ha la costumbre quando es puesta con razon. Asi como diximos, ca las contiendas que los omes an entre si de que non fablan las leyes escritas pueden ser librar por la costumbre que fuese usada sobre las razones sobre que fue la contienda, e aun ha fuerza de ley. Otrosi dezimos que la costumbre puede interpretar la ley quando acaesciese dubda sobre ella, que ansi como acostumbraron los otros de la entender, ansi deve ser entendida e guardada. E aun ha otro poderio muy grande que puede tirar leyes antiguas que fuesen fechas antes que ellas, pues que el rey de la tierra lo consintiese usar contra ellas tanto tiempo como sobre dicho es o mayor. Esto se deve entender quando la costumbre fuese usada generalmente en todo el reyno. Mas si la costumbre fuese especial, estonce no se desataria la ley. E desatase la costumbre en dos maneras aunque sea buena. La primera, por otra costumbre que sea usada contra aquella que era primeramente puesta por mandado del señor e con plazer de los de la tierra, entendiendo que era mas su pro que la primera segund el tiempo e la sazon en que se la usasen. La segunda, su fuesen despues fechasleyes escritas o fuero que sean contrarios della, ca estonce deven ser guardadas las leyes o el fuero que fueron despues fechas e non la costumbre antigua”. 
planteo de la duda sobre la costumbre. Si bien no señala en qué pudiera consistir, aparece un concepto que no se asocia nunca a la ley y que disminuye la prerrogativa de la costumbre como algo incierto y sujeto a diversas visiones. El segundo "poderio" de la costumbre es el desatar la ley. Esta construcción está, una vez más, cargada de "peros". En rigor, la costumbre solo desata a la ley cuando lo consiente el rey y cuando tiene aplicación para todo el reino. En primer lugar, plantea una esfera puramente regia, intacta, en torno a hacer la ley y a derogarla. De tal modo, no puede quedar librada al juez local esta tarea, pues debe notificarse al rey y, más aún, solicitar su conformidad. Por lo tanto, la derogación no es automática mientras que, según lo expuesto en el título anterior, la ley se establece sin tomar en consideración a otras expresiones jurídicas previas y/o locales. De esto se desprende una segunda cuestión: la costumbre como general de todo el reino. Así, esta ley contradice todas las definiciones que viene dando en torno a la formación de estas normas o coloca a la costumbre en una esfera indeterminada ¿Cómo la costumbre se generaliza a todo el reino teniendo en cuenta sus requisitos de corroboración? Quizá pueda ser determinada en parte por la materia que trate la costumbre, pero nada de eso aclara, solo dice que si es especial, i. e. particular, local, no desata nada, excepto para ese lugar y, por tanto, se contradice con lo primero que explicitó.

En definitiva, al mencionar al principio la posibilidad de derogación de estas tres instancias no explaya modos para el 'uso' y complejiza su definición y aplicación. Posteriormente, al sostener lo propio para la costumbre, plantea que solo puede derogar la ley cuando su validez es para todo el reino y en consecuencia el rey debe aceptar este cambio y, si no, no valdría. Por lo tanto, la costumbre, en este punto, se diferenciaría poco de la propia ley cuando quisiere "embargarla", pues debe ser general y posibilitada por el propio rey (aunque, claro, su factura no se origina en él). Además, en medio de la definición de la derogación de la ley por la costumbre introduce la variable temporal. Dicha variable no aparece como obligatoria, pero aclara que la costumbre actúa cuando la ley es "muy vieja" (una vez más plantea un elemento de importancia con una carga de indefinición considerable). En algún punto, el tópico de la vetustez de la ley se hace camino y la costumbre parecería canalizar la propia dinámica de la ley. En lo concerniente a la derogación de una consuetudo particular por otra nueva que trate sobre la misma materia aparece una dinámica clara y que permite el proceso con total automatismo siempre que cumpla con los requisitos pertinentes (aunque los reduce considerablemente cuando plantea que al tratar lo mismo bastará para que la nueva costumbre derogue a la antigua que "nadie", i. e. nadie del lugar afectado, levante la voz en su contra). Sin embargo, al final plantea que si una ley se hiciera 
a posteriori, inmediatamente ipso facto queda sin valor la costumbre. Sumando todo esto al factor tiempo, crucial en este debate, la ley abre camino a una potencial competencia desigual entre instancias normativas. La razón estriba en que la costumbre debe cumplir cuantiosos requisitos complejos para derogar la ley, mientras que esta última deroga a la costumbre de modo automático en cuanto se crea. Así, al derogar una costumbre a una ley por ser antigua, una nueva ley que contradiga a la "costumbre derogadora" la deja sin efecto inmediatamente y, al ser nueva la ley, ya no hay lugar para una nueva consuetudo que vuelva a derogarla. Este círculo de complejidad no hace más que oscurecer la regulación de expresiones jurídicas que están en clara competencia. Deliberado o no, lo cierto es que esto muestra un proceso de subsunción normativa.

La ley séptima es la que define al fuero, que "encierra dos cosas que avemos dicho, uso e costumbre, e cada una dellas a de entrar en fuero para ser firme" ( $P$. I, II, 7). Una vez más, la trascendencia de la norma local debe subsumirse a un último proceso de valorización. El fuero, en este caso se define en el texto alfonsí, por medio de la etimología, como el espacio de lo público. Es decir, el carácter que adquiere una norma a partir de su puesta en publicidad. Por tanto, el fuero le da entidad y permanencia a las otras expresiones jurídicas (como las costumbres) en la medida que produce conocimiento, para todos los del "pueblo", sobre la materia tratada y debe, además, observar al derecho en su factura. Aparece nuevamente la juridización del proceso creativo, ya que esa "observancia del derecho" para la realización del fuero proviene de la intervención de los jueces, y el fuero entonces pierde vigencia en caso de no pertenecer "señaladamentre" al derecho. Por tanto, el fuero es también encerrado dentro del juego de tecnicismo jurídico que es arma en el combate del rey Sabio. La ley siguiente, "Como se debe fazer el fuero" ahonda más en esta idea. Así, nombra explícitamente a los sabidores del derecho y agrega que todos los habitantes sobre los que se yergue la norma deben estar de acuerdo. Estos procedimientos especificativos le dan una imprecisión y complejidad al proceso, desde la littera jurídica, que resultan dignos de mención.

La derogación del fuero en la ley 9 posee una imprecisión no menor. En este caso, se define el embargo cuando fuese "malo". Los tres juzgadores de lo bueno y lo malo son Dios, el señor natural y el pro de la tierra, este último como elemento abstracto. Finaliza explicitando que cuanto más tiempo funcione un fuero malo peor será el daño y más peligroso. Por tanto, la derogación de dicha expresión normativa se hace más fácil para el "Seńor Natural" siendo que la carga de negatividad expresada es muy grande para aquellos fueros que caen en la categoría de "mal hechos", que se definen, justamente, por no "catar" lo que Dios, el "Señor Natural" o el pro de la tierra expresan. 
En definitiva, si debiéramos solamente quedarnos con lo dicho en el proemio de este título II, veríamos que el uso, la costumbre y el fuero pueden derogar leyes y pueden igualarse también a ellas. Sin embargo, en el análisis más pormenorizado del contenido y de la construcción de los razonamientos, vimos que estas instancias normativas están por debajo de la ley en cuanto al funcionamiento concreto de sanción y "embargo". Esto no invalida la hipótesis de ver la inclusión de este título como un síntoma del fracaso materializado en la capitulaciones de I272, pero muestra que sigue vigente el concepto de "perfectibilidad" del proyecto alfonsí, aunque la pelea se traslade a un plano más elevado. De tal modo, la ley la hace el rey y desata ipso facto todo lo que la contradiga. Cuando sucede lo contrario, siendo tan impersonal como indeterminado el sujeto del uso, costumbre y el fuero, aparecen metodologías complejas y excepciones constantes donde a la par que se produce la tecnificación de la creación jurídica, se le otorga a la ley y al rey condiciones mucho más accesibles para "dar vuelta" esas otras instancias normativas.

\section{LA LEY Y LA COSTUMBRE EN LAS PARTIDAS DEL SIGLO XVI}

El contexto en que Gregorio López realizó su edición es bien distinto al otrora vivido por Alfonso X. Alrededor de trescientos años más tarde, el emperador que poseyera la mayor extensión de tierra habitada de toda la historia hasta entonces conocida, era protagonista, asimismo, de su mayor fracaso político. Este ambiente hostil donde España se sentía, prácticamente desde la propia asunción de Carlos, particularmente desatendida es el que ve nacer la edición de 1555, un tiempo antes de la abdicación. ${ }^{16}$ El elegido para dicha tarea fue el Licenciado Gregorio López $^{17}$ y fue en realidad la hija menor de Carlos V, Juana de Austria, regente

${ }^{16}$ Véase Rodríguez Salgado (1988).

${ }^{17}$ Gregorio López, llamado el Accursio español, fue un jurista muy importante en su época y estuvo a cargo de la edición más completa y erudita de las Siete Partidas, hasta ahora conocida. Su aparato no solo posee gran erudición sino que, además, completa las remisiones del texto, que los redactores originales obviaron, de un modo completo, aunque sea un poco anacrónico por momentos. Nacido en Guadalupe en I496, fue humanista, jurista y abogado, miembro del Consejo Real de Indias, gobernador de los estados del Duque de Béjar, fiscal del Consejo de Castilla y abogado de la Real Chancillería de Granada. Es imprescindible no confundirlo con su nieto de nombre homónimo, quien puede ser reconocido a partir del genitivo "de Tovar". Este último fue el encargado de cambios en el índice de las reediciones de la obra de 1555 desde los ańos I575 a 1587 . Los datos personales sobre este importante jurista español que se encargó de glosar Partidas en I555 no abundan. Para conocer detalles de su vida privada y de su cursus honorum, véase Rumeu de Armas (I993-I994). 
de la corona española desde 1554 hasta 1559, quien encargó la obra. Esta edición estaba pensada en medio de la crisis política generada por la ausencia de Carlos I. A este contexto debe sumarse la situación económica tras las derrotas militares que desde 1548 se venían produciendo. Para esas contiendas España aportó gran cantidad de fortuna pero no consiguió mayor rédito. Carlos se encontraba en los Países Bajos de forma permanente ya desde la década del '40 y Felipe, heredero de la corona, se hallaba en tierras anglosajonas, para disponer su casamiento con la reciente reina inglesa María I Tudor. Padre e hijo se juntaron con vistas a las escénicas abdicaciones montadas una tras otra en cada parte del territorio que sería cedido. Desde 1554 y hasta 1556 , los monarcas, el presente y en vías de ausentarse y el sucesor en proceso de constituirse, "brillaron por su ausencia" en tierra ibéricas. Así, sostiene Rodríguez Velasco (20IO, p. II9): "Las dos ediciones impresas de las Partidas en I49I y I555 se nutren de los conceptos constitucionales de éstas, en particular del modo en que ha sido compuesta la teoría del poder monárquico sobre la base de la persona regia como imago legis". La crisis a la que hacemos referencia explica la producción discursiva en tanto que el corpus iuris se lleva a cabo como metonimia del corpus regis ausente. Este es el objetivo de la presencia producida por la reedición de la obra. Resulta claro así que aunque la edición (obra) se explique por vía del poder simbólico que posee Partidas (texto), el análisis de las glosas nos introduce en una dimensión más práctica y concreta que tiene que ver con el "llenado" jurídico real para el siglo xvi de la obra política del siglo XIII. Así, se edita y se glosa para ocupar el contenido de la obra alfonsí, que explica su presencia como un elemento simbólico que sirve para llenar, a su vez, el vacío concreto generado por el rey Carlos I. ${ }^{18}$

En cuanto al pautado, la edición de 1555 responde al formato de texto tutor a dos columnas con texto encuadrante también a dos columnas. Cuenta con veinticuatro títulos y foliación marcada desde 3 r. En cuanto al comentario marginal, este es en latín, y aunque Díaz de Montalvo también establece una aparato de comentarios en esa lengua, habría detrás de esas remisiones e intervenciones del siglo xv una intención "hispanizadora" hacia el texto de Partidas, mientras que en el siglo XVI, López tendría, según opinión generalizada de la crítica, una pretensión de separarse de esa tradición propiamente hispánica para integrar el

${ }^{18}$ Recurro al concepto de "producción de presencia" de Gumbrecht (2004) en la medida que proporciona la explicación necesaria para entender un funcionamiento simbólico a partir de un hecho material donde no aparece en primer plano el contenido, sino, justamente, los aspectos formales. Una vez más, igual que con Alfonso compilando el basamento de la unidad política y jurídica, es el libro en sí mismo el objeto de la operación. 
cuerpo legal alfonsí dentro de otra tradición: la romanista europea. ${ }^{\text {I9 }}$ Se plantearía entonces una gran transformación. De ese modo, Rodríguez Velasco (2010, pp. I25-I26) entiende que López, en I555,

quiere separarse por completo del derecho castellano para integrar el cuerpo legal alfonsí en la tradición romanista europea. Se trata de una gran transformación de la tradición. Las Partidas tienen fuentes muy diversas y en gran medida polifónicas, y entre ellas se cuentan partes amplísimas del Corpus iuris civilis y del Corpus iuris canonici, pero no son menos importantes las fuentes historiográficas, la Ética de Aristóteles, los textos bíblicos, textos científicos y, en términos generales, textos y glosarios que transitan por el complejo e ilimitado taller alfonsí. Sin embargo, las Partidas hacen desaparecer esas fuentes, borrándola $[\mathrm{s}]$ o relegándolas a menciones inespecíficas, justamente al contrario de lo que sucede en el ámbito de los glosadores del derecho romano, o en la propia compilación del Corpus iuris civilis, en la que cada ley es situada dentro del ámbito imperial en que se originó. Con ese sistema, las Partidas habían nacido como un derecho propiamente castellano en lengua castellana. Así conviene entenderlo: las fuentes no aherrojan a los escritores de las Partidas ni los sujetan a la constitucionalidad imperial heredada, sino que con todo ello elaboran una definición innovadora de la jurisdicción y la presencia de la monarquía en todo el territorio. El proceso de difusión hasta I49I se mantuvo en esa línea, en la cual se podía reconocer la constitucionalidad de la pieza legal, la especificidad castellana de la definición del poder basado en la jurisdicción central. Incorporarlo al derecho romano supone una voluntad de internacionalización del derecho castellano, y, aún más importante, supone una voluntad de incorporación de este derecho a la fuente y origen del derecho imperial, a la tradición del Corpus iuris civilis. Se trata, pues, de la emisión de un derecho imperial estrictamente castellano en su marco del derecho imperial romano. Es una tesis casi muda sobre el emergente imperio transatlántico español, sobre la definición de poder del mismo y sobre su presencia en la geografía y en la historia del imperio.

Una pregunta interesante podría ser cómo la misma lengua, el uso del latín en el aparato, es síntoma de dos fenómenos distintos según cambia el editor y la época. A partir de esta pregunta podemos inferir que es un error basarse solo en el uso del latín para entender estas prácticas. Por tanto, lo que deberemos mirar es concretamente los cambios ocurridos sobre la práctica forense en los respectivos aparatos. Utilizando esto como puntapié inicial, debemos decir que consideramos que a la propuesta interpretativa de Rodríguez Velasco habría que añadir-

19 Corresponde aclarar que la edición de Díaz de Montalvo († I499) original de I49i no poseía glosa, la misma se termina un año después y se integra por primera vez en I5OI. La reedición que hemos trabajado es la de I528. A diferencia de lo ocurrido con López, no hemos encontrado en su tradición cambios significativos como para desecharla como ocurre con las homólogas de López posteriores a su muerte. 
le algunos matices, aunque no reduzcan su potencial aplicación. Las fuentes ya harto conocidas de Partidas no explican por sí mismas la labor de López. De tal modo, se señala una continuidad donde hay dos procesos distintos. Por un lado, el de codificar convirtiendo en propios los textos recuperados, haciéndolos dialogar y mezclándolos con otras fuentes cruciales del siglo XiIr. Por otro lado, el de la tecnificación propia del siglo XVI en torno a la forma de "hacer derecho" asociada a los corpora estables de éste, elementos desconocidos, estos últimos, como tales en época alfonsí. A su vez, la propuesta de Rodríguez Velasco sí está diciendo que, en todo caso, la obra original de Partidas posee tan amplia gama de fuentes que, en todo caso, o es "algo" distinto (y por tanto propiamente hispánico) o es un complejo e interesante ius proprium. En cualquier caso, la propia Partidas tiene tradiciones que una u otra perspectiva pueden revitalizar sin determinar toda la labor hacia un sentido u otro por medio de la intención del editor. Si miramos, por ejemplo, la proliferación de codificaciones europeas del siglo XIII (el florecimiento de la codificación como lo llama Wolf, 1989 y 1993-1994), Partidas aparece como modelo unos pocos años después de gestada su primera redacción. Esto es algo que se puede observar en el código de Magnus Lagaboetir de I277. ${ }^{20}$ Más allá de lo expuesto queda todavía en consideración la intención de la obra de López. Como ya hemos expuesto, pensamos que la visión de Rodríguez Velasco sobre el trabajo de López debería, cuando menos, matizarse. Nuestro rechazo no es total, pero lo que tratamos de decir es que, en principio, habría una explicación mucho más contextual y relacionada con las prácticas jurídicas y forenses de cada época más que propiamente con una intención política determinante. Asimismo, sí consideramos que existe una intención específica, pero adelantamos que dicha intención implica comunicar un mensaje "imperial” propiamente español en el escenario internacional. Ese imperio es el que se proyecta desde Espańa hacia América y no el que comprende los dominios transpirenaicos carolinos. Entonces, hay dos aspectos para analizar. Por un lado, todo aquello que implica mostrar las fuentes del derecho, según el uso aceptado y necesario que estudiaban los juristas del siglo xvi. Por otro lado, el comentario in extenso que implica la intervención de López, i. e. de los intereses que representaba, en el texto de Partidas. Ambos elementos están en el mismo lugar, pero no constituyen necesariamente

${ }^{20}$ Más allá de lo dicho por el propio Wolf (I993-I994, p. 38) constatamos en Bagge (20IO, pp. 219-223) la relación entre los textos mencionados. Ese estudio es general y se refiere a la conformación del Estado noruego en el siglo xiII en relación a la codificación jurídica. La homologación del proceso la toma por automática, y la conexión textual concreta, en realidad, se encuentra en otros autores, pero por desconocer el noruego se nos hace imposible acceder a su lectura. 
un mismo objeto de estudio. En este sentido, no vemos a la edición como una plataforma jurídica al mundo ni como un código que pretendiese usarse en las más remotas escuelas de derecho, sino como un objeto de operaciones políticas que mostraba aquello que era necesario para habilitar un escenario de revalorización monárquica propiamente español.

Más allá de esto, es moneda común decir que Partidas silencia sus afluentes intelectuales mediante la inexistencia de referencias. Nuevamente se pone en primer plano la intención. Con este recurso la obra jurídica del rey Sabio se presentaría como algo original y propiamente castellano y, en ese contexto, el uso de la lengua romance resultaría esencial. ${ }^{2 \mathrm{I}}$ Precisamente, será este procedimiento el que le permita a Alfonso no sujetarse a las fuentes ni a la "constitucionalidad imperial heredada, sino que con todo ello elabora una definición innovadora de la jurisdicción [centralizada] y la presencia de la monarquía en todo el territorio" (Rodríguez Velasco, 20I0, p. I25).

El objetivo de López, bien visto por Rodríguez Velasco, era centrar la lectura e intervención en cuestiones relacionadas con el territorio americano, pero no desde una óptica imperial de su propio tiempo, sino desde otra puramente monárquica atando esos territorios conquistados a la Corona castellana. El pensamiento político español nunca genera, de modo independiente, una noción de imperio por fuera de ligar territorios a la Corona centralizadora de Castilla. Por ello, Partidas integrará la compilación jurídica dada a Las Indias, cosa muy bien conocida por el consejero de Indias Gregorio López. De tal modo, tanto en la aceptación como en la por momentos beligerante contraposición, la glosa produce una adecuación de tradiciones donde lo romano y lo castellano se resignifican. Así, da cuenta de las diferencias entre esas dos realidades históricas. Explica Rodríguez Velasco (20IO: p. I22): que "en ese micro-espacio se debate el modo de enfrentarse

${ }^{21}$ Cierto es también que la crítica durante mucho tiempo, al menos Iglesia Ferreirós (1984), consideró probable que existiera, para la edición (o ediciones), posterior a 1272 un plan de traducción al latín al estilo Liber Augustalis. Sin embargo, es pura conjetura y ya nadie sostiene esto, quizá por falta de fuentes, pero principalmente porque no tiene sentido a efectos de un estudio sobre la recepción. Si bien son cuestiones poco abordadas, en el estado actual del conocimiento Las Partidas son vistas, para los años finales del reinado alfonsí, como un objeto de lucha "nacional". Esto último, sí, quizá cambie con la glosa de López. No pensando en introducirla en una tradición, repito, sino como portavoz de una posición y de una determinada pretensión políticas. Vale decir también, que formaba parte del proyecto de Fernando III, continuado en Alfonso, que todo aquello que correspondía al derecho y la monarquía fuese producido (y traducido cuando proviniera de otro contexto) al "castellano derecho". Así, la propia lengua, su presencia, era un arma política de la monarquía del siglo XIII y de la posterior. De tal modo, el castellano no es un elemento más en la búsqueda de originalidad de las Partidas, sino un elemento basal de la construcción política monárquica en España durante siglos. 
con la presencia imponente de Alfonso X, cuya teoría del poder monárquico y de la centralización jurisdiccional forman parte constitutiva de los criterios absolutistas de la Edad Moderna”. De este modo, postulamos que el acomodamiento de los contenidos, la elección de manuscritos y sus tradiciones tanto como de variantes y asimismo el contenido del texto fuente para discutir en la glosa con su exposición de la lengua latina conforman una nueva intención, la de Gregorio López. Pasemos ahora al análisis textual para ver dichas intervenciones.

La edición de López posee dos rasgos característicos. En primer lugar, repone con amplios niveles de exactitud y erudición las remisiones que los redactores de las Partidas omitieron de forma deliberada. En segundo lugar, presenta en su trabajo completo un claro intento de resemantización del texto original. Esto último, centro de nuestra investigación, nos guiará la lectura para el caso de la costumbre.

Ahora bien, en un siglo xvi bajo el poderío de la casa de Habsburgo en España, cabe preguntarse qué papel desempeña el problema de la costumbre en relación al poder del rey. Una respuesta aproximada la podemos obtener al leer ya la primera glosa ad verbum "uso" (P. I, II, pr.). Dentro del texto de Partidas, el comentario de López produce de forma temprana una interrupción textual en la lista de elementos que "embargan" la ley. De tal modo, explicita (corrigiendo el texto alfonsí) que el uso es un hecho sin fuerza normativa y, por tanto, carece de la potencia necesaria que sí tiene la consuetudo. Por otra parte, condiciona la existencia de la costumbre a la posibilidad concreta de demostrar el uso. Por lo tanto, en esta primera aparición está mostrando una relación constitutiva entre los elementos jurídicos, pero descartando que funcionen de modo independiente como ius. Por ello, el simple factum no deroga nada. Asimismo, debe de poder probárselo para admitir a la costumbre como válida. Inmediatamente López ordena la definición confusa de Alfonso X. En la glosa siguiente, adelanta elementos enunciados por el rey Sabio para definir el tiempo. Si bien es cierto que relaciona el texto alfonsí en este punto con el Digesto (I. III. 32), lo que pone en un primer plano es la exigencia de la continuación del uso que constituye la costumbre. Además, cerca esta expresión jurídica dentro de los límites del derecho recuperado. La littera de Juliano expresa que De quibus causis scriptis legibus non utimur, id custodiri oportet, quod moribus et consutudine inductum est, et si qua in re hoc deficeret, tunc quod proximum et consequens ei est, si nec id quidem appareat, tunc ius, quo urbs Roma utilitur, servari oportet. ${ }^{22}$ La cita elegida por López pone

\footnotetext{
22 "En aquellas causas que la ley escrita no es utilizada, debe observarse lo que por uso [moribus] y costumbre [consuetudine] es introducido. Y, si faltare en algún punto, entonces que sea lo que es
} 
de manifiesto dos cosas. En primer lugar, un carácter absolutamente supletorio de la costumbre, y, en segundo lugar, un juego de referencias con la ciudad de Roma que, en términos concretos para la época en la que escribe, no conduce a ningún lado. La ley está reglando un ius imperial. Así, si positivamente no hubiera nada entre las leyes para solventar el problema suscitado, entonces se debía recurrir a la consuetudo. En caso de no poder probarse o usarse, la glosa reenvía al derecho civil de Roma. En todo caso, hace concurrir el impreciso tacitus populi consensus para sostener una normatividad por debajo de la ley en tanto que resuelve problemas de modo supletorio. Nada dice hasta aquí sobre la derogación. La glosa siguiente ad verbum "fuero" remite a la ley séptima. Este procedimiento no tan habitual en López genera una suerte de salto en la lectura hacia la ley que, por lo que veremos después, trata al verdadero derecho, el fuero. ${ }^{23}$

En rigor, la glosa no hace más que especificar con mayor énfasis la inscripción jurídica de la validación del uso, la costumbre y el fuero. ${ }^{24}$ En las glosas contiguas ad verba "uso" y "cosas" continúa con las definiciones. López reniega de la acepción de uso que plantea Alfonso pues entiende que implica un uso particular. Por ello, sostiene que el uso de una persona, sea quien sea, no constituye derecho sino es realizada por la mayoría del lugar, Ergo, plures actus requiruntur ad inducendam consuetudinem. ${ }^{25}$ Nuevamente aparece el elemento temporal, ya que no es cuestión de muchos actos en un solo tiempo, sino de aquellos sostenidos por muchas personas y a lo largo de mucho tiempo. Sin embargo, se mantiene la definición imprecisa en lo que respecta a la determinación del número de personas y de la cantidad de tiempo. Otro elemento recurrente es la especificación de circunstancias que invalidan la consuetudo. Por ejemplo, donde Alfonso decía "e sin embargo ninguno" (haciendo referencia a lo necesario para que la costumbre sea válida), López en la glosa ad verbum "ninguno" (P. I, II, I) especifica un caso posible y cotidiano, la coacción, y reafirma nuevamente el poder del juez para

próximo y consecuente, si esto tampoco apareciera, entonces derecho, aquel que utiliza Roma”. Alegado en glosa ad verbum continuadamente, $P$. I, II, I.

${ }^{23}$ Sí es usual el reenvío previa argumentación como se observa, por ejemplo, en el tratamiento de la temática canónica de los títulos siguientes.

${ }^{24}$ En este sentido, lo que aparece es una determinación a priori de qué sirve y qué no sirve para realizar consuetudo. De este modo, lo que aparece constantemente como signo del carácter popular no es más que la determinación desde otro lugar de qué convierte a algo en popular, especificando número de actos, finalidad, cantidad de años en uso, edades, géneros, etc. ( $P$. I, II, I glosas ad verba "uso", "continuadamente" y "ninguno" y P. I, II, 2 glosas ad verba "comunal”, "escondido" y "derecho").

${ }^{25}$ "Por lo tanto, son muchos los actos requeridos para inducir costumbre". 
disponer ante situaciones no previstas. En la glosa ad verbum "conocido" (P. I, II, 2) resuelve el problema del tacitus consensus populi, pero parte, no de definirlo, sino de darlo por entendido y plantea la necesaria publicidad del uso para que pueda servir para formar consuetudo. De tal modo, aquello que hacen todos y por mucho tiempo posee visibilidad y de allí su status potencial de norma en la medida que nadie impugne el hecho. El factor de publicidad tiene un lugar trascendental, pues si todos negasen la práctica no podría adquirir carácter de consuetudo. Pero, una vez más, induce a la contradicción, pues si muchos y visiblemente a vista de la totalidad deben realizar un acto por mucho tiempo, ¿cómo entender que otros muchos lo puedan, a su vez, negar? Todo se resuelve, de nuevo, por el arbitrio judicial en el marco de conflictos concretos y particulares en torno a las prácticas que la consuetudo viene a regular. Como hemos visto anteriormente, la presencia del juez se vuelve a asegurar para definir a la costumbre al explicar el problema, ya presente en la propia ley, de la coacción ("e sin embargo ninguno"). Así, López considera que si la costumbre adquiere carácter de norma, manda; si manda, necesariamente ejerce fuerza, incluso si esta coacción la ejerce toda la comunidad con una o más personas en ella que la contradigan. Por lo tanto, en todo caso debe resolver el juez, ya que allí se juzga el problema de la reprensión de la coacción individual y no de la institucional (coactio siat per iudicem per viam iurisdictionis an per privatum [...], [en rigor] quod enim facit iudex, totus populus facere videtur, cum iudex sit auctoritate populi praepositus (P. I, II, I glosa ad verbum ninguno). ${ }^{26}$ Podemos ver que nuevamente encontramos un énfasis en la regulación de los procesos de conformación que se atienen de modo excluyente a la actividad jurídicamente explicable y llevada a cabo.

En la glosa ad verbum "escondido", López vuelve a tratar de definir el carácter público del acto constituyente y el concepto de consenso. De aquí que, tras la referencia de la glosa anterior al objetivo de la costumbre, debe acercarse al de la ley, el bien público y la utilidad, va delineando mejor el límite normativo. De ese modo, plantea que cualquier derecho o empresa expresada en un espacio debe poseer tal utilidad que todos lo puedan usar o gozar, de modo que queda absolutamente relegada la iniciativa del poder privado para establecer jurisdicción. Adoptada esta posición, el derecho le da a la comunidad, que descansa en la presencia del juez validador, un poder de regulación que no se puede subsumir en una mera expresión de formalización de un poder señorial.

${ }^{26}$ "Por consiguiente, parece conveniente que el pueblo en su totalidad haga lo que hace el juez, siendo que el juez tiene mayor autoridad que el pueblo". 
En la extensa glosa ad verbum "bien" (P. I, II, 3) parecería definir mejor la noción de iurisdictio que podría operar en el siglo XVI:

Namque inducere prauitatem et peccata et absurditates, non causaretur ex eis consuetudo seruabilis [...], [asimismo], Quae autem consuetudo dicatur rationabilis vel irrationabilis relinquitur arbitrio iudicis [...], [en este sentido], est communis opinio et ponderabit iudex vtrum finis consuetudinis, sit bonus vel malus, an sit contra ius vel praeter, et an ex aliqua ratione iusta fuit inducta. Vtrum ius approbet vel reprobet similem consuetudinem et consideratis diuersis rationibus, potest consuetudo esse rationabilis, etiam contra legem rationabilem tradit. ${ }^{27}$

De la cita podemos sacar en limpio que la racionalidad de la norma y su ordenamiento a derecho es lo que prima, aun cuando contradiga la ley, ya que esta última no puede contemplar todos los casos particulares. Tan lejos está esta glosa de plantear un imperio de la voluntad legislativa como de dejar asentada la invariabilidad de la costumbre. En rigor, para este jurista toda la responsabilidad recaería en el juez. Más allá de esto, lo que podemos resaltar es la "distancia política” que se puede leer en López con respecto a la dialéctica entre instancias jurídicas que estaba tan presente en el texto de Alfonso X. El trabajo de este jurista registra un estado de norma en un tiempo en que el derecho tiene como máxima preocupación constituir base de poder. Estamos, con evidencia, en un tiempo de normalidad jurídica, de una preocupación central por la regulación del conflicto. En ese sentido, la ley y la costumbre se encuentran muy distantes entre sí como para entenderlas a ambas dentro de un mismo orden. Es decir, la costumbre dejó de ser aquello que los sectores nobiliarios podían apelar contra la imposición "foránea". Ahora, el juez con toda la carga institucional de una monarquía centralizada es el protagonista. Así, es el juez quien tiene la última palabra y esto se relaciona con lo que venimos planteando en torno a la naturaleza de la consuetudo y su proceso ya completado de adscripción, no a un supuesto origen

\footnotetext{
${ }^{27}$ Para evitar el anacoluto presente en el texto hacemos una propuesta sintáctica: Et ponderabit iudex vtrum finis consuetudinis, sit bonus vel malus, an sit contra ius vel praeter, et an ex aliqua ratione iusta fuit inducta. [Iudex ponderabit] utrum ius approbet vel reprobet similen consuetudinem. Et, consideratis diuersis rationibus [potest consuetudo esse rationabilis etiam contra legem], [consuestudinem] rationabilem tradit. Aunque no la incluyamos en la traducción, nos sirve de apoyo para lograr un mejor sentido: "con lo que indujera maldad, pecado o absurdo no se conformaría causa de consuetudo que fuera útil. Ahora bien, en lo referido a la sentencia de racionalidad o irracionalidad queda al arbitrio del juez. Esta es la opinión común: el juez considerará si el fin de la consuetudo es bueno o malo, si es contra derecho o va más allá de él, y si su introducción es causa justa. El derecho aprobará o no tal costumbre. De allí, delibera si dicha costumbre es razonable, aún contra la ley”.
} 
comunal anterior, sino al arribo del Corpus Iuris. Por ello, más adelante en la glosa ad verbum "consejo" (P. I, II, 3) López da por sentada la base de la creación de la costumbre: tam iuris communis quam iste partitarum ita exigant certam scientiam populi in inducenda consuetudine, et ubi est talis error ${ }^{28}$ non est consensus populi, in ipsa consuetudine inducenda. ${ }^{29}$ Así, lo que prevalece es la ciencia que, como dice en esta glosa, es requerida tanto por el derecho común como por las Partidas. En este sentido, destaca que si se introduce una consuetudo mal hecha por pensarse que es acorde a la ley, inmediatamente es rechazada, pues no decide la comunidad sobre su validez. Solo es válida aquella que se atiene a las prácticas del derecho y en correspondencia con la ley. Por ello, lo que en Alfonso se define como consejo, en López se determina como técnica. Cuando la ley indica la avenencia de los que "en cuyo poder son", López explicita (ad verbum "son") que se trata de magistrados y de jueces que ordenan y mandan a los "ciudadanos" (iurisdictioni cives subsunt). Sin embargo, le coloca un límite a ese poder judicial al establecer, entonces, que debe existir consenso, aunque alcanza con que sea tácito, es decir, que no se establezca causa en contra.

En lo que refiere a la relación con el poder del rey, la glosa ad verbum "establecidos" ( $P$ I I, II, 3) deja claro, en referencia a la costumbre que puede ir contra el derecho que: si vero rex ignoret vel contradicat, non potest induci consuetudo contra. ${ }^{30}$ Y sigue, glosa ad verbum "plaziendole" (P. I, II, 3):

cum enim violare statuta regum sit peccatum [...], requiritur qua consuetudo inducatur de voluntate illius, qui nouam legem et nouam consuetudinem inducere potest, neque sufficiet toleratio simplex [...], [y define], quia cum hodie solus princeps faciat legem, [por lo tanto], ideo consuetudo non valebit, nisi inducta sit, de conscientia principis.

Este principio general y absoluto, sin embargo, encuentra un límite en las concesiones que el propio príncipe hace en materia estatutaria. Es decir, López aclara una redundancia: si el rey dio permiso a un lugar (ciudad concreta) de

${ }^{28}$ Definido previamente y referido al procedimiento de introducción de la costumbre en relación a su causa final.

29 "De este modo, tanto el Derecho Común [Corpus Iuris] como esta Partida exigen cierta ciencia al pueblo al hacer una costumbre, y donde haya un error no se puede decir que sea consenso popular en la introducción de la costumbre".

${ }^{30}$ "Si en verdad el rey ignora o contradice, no se puede introducir costumbre en contra".

${ }_{31}$ "Como violar los estatutos reales es pecado se requiere que dicha costumbre posea la voluntad del que puede hacer ley y costumbre nueva, no siendo suficiente el simple hecho de tolerarla. El único que puede hacer leyes es el príncipe; así sólo vale la costumbre que tiene permiso consciente del príncipe". 
que realice sus propios estatutos, y siendo que lo hace conduciéndose mediante la ciencia (jurídica) y observando los dichos de los jueces, no hará falta el seguimiento ni nuevo consentimiento del rey. No obstante, como deja bien claro en la glosa anterior, la costumbre no puede establecerse contra el derecho, que López entiende explícitamente como derecho positivo, ni contra las leyes del rey.

Ya hemos seńalado que Alfonso define en $P$. I, II, 4 a la costumbre como derecho. En esto, sigue lo dicho por Azo. Sin embargo, López aclara, en esa misma ley, en la glosa ad verbum "derecho", en correspondencia con Abbas Antiquus ( $\dagger$ 1296), que esa sentencia se refiere al: compromisso facto in arbitros ut pronuntient secundum ius quod poterunt pronuntiare secundum consuetudinem. ${ }^{32}$ Esta oración muestra una relación de igualdad entre costumbre y derecho, siempre y cuando la costumbre se refleje en el ius. En otras palabras, derecho y consuetudo aparecen igualados en la medida que todos los "árbitros" deben tener presente lo avalado por el derecho al momento de sentenciar alegando costumbre. Así de lo particular se pasa a lo general y los fallos de los jueces que observan la costumbre para dirimir cuestiones específicas dentro de sus jurisdicciones responden fundamentalmente desde el derecho.

Las glosas que siguen retomarán las mismas cuestiones abordando la totalidad de temáticas en torno a la costumbre. Una digna de mención es la ad verbum "señorio" de P. I, II, 5. Allí, López interpreta directamente esta instancia como la majestad real. Por tanto dice: Non ergo valet consuetudo contra maioriam regis et regni seu contra suprema iurisdictionem. ${ }^{33}$ Como venimos planteando, el tiempo es

32 "Compromiso hecho en los árbitros para que sentencien de acuerdo con el derecho, aquello que pudieron sentenciar siguiendo la costumbre".

33 "No vale, por lo tanto, la costumbre contra la mayoría del rey y del reino o contra la suprema jurisdicción". La inexacta traducción, para el estado actual de nuestra lengua, de majoriam por "mayoría" obliga a precisar someramente lo que pensamos al respecto. La noción de majoria resulta un tanto compleja. En la edición traducida y comentada de I843 sobre esta de López aparece traducida como "soberanía", lo cual me parece excesivo aunque, debo decir, de un modo relativo ya que no parece tan errado desde el punto de vista semántico. La palabra maior no designa, en su uso para la composición de la palabra majestas, un estado relativo como superioritas (aunque esta última sea la que provea el étimo a "soberanía" para darle su entidad morfológica actual). Una de las mayores contribuciones al lenguaje político que hizo la Edad Media fue la de tomar un campo semántico que estaba referido a la esfera de lo divino (e inmaterial) y adaptarlo al ámbito de lo regio o imperial. La noción de majestas (del estado mayestático) se compone del étimo indoeuropeo "meg-" que implica un estado máximo, absoluto (dentro de este mismo campo se encuentra maior, magnus, etc. cfr. entrada I240, p. 708 del Indogermanisches Etymologisches Woerterbuch de Julius Pokorny). Puede verse esto en sus derivados, como majoralis, majorare, majoratus, majorinus, majoritas que significan respectivamente "los grandes", "incrementar", "dignidad de senescal", "delegado regio con poderes judiciales" ("merino”), "estado aumentado, incrementado"; majestas proviene de esta misma 
otro y la asociación directa a la noción de jurisdicción suprema (devenida de los conceptos de iurisdictio plenissima y plenitudo potestatis) nos muestra que la "pelea jurisdiccional" hacia el interior del reino ya estaba definida hacía tiempo. De este modo, se expone en la glosa de López, por medio de la ratificación del contenido alfonsí, una maximización de la diferencia entre espacios jurisdiccionales que introduce nuevos elementos que funcionan agregando cualidad al contraste que marcan.

Al comenzar a explicitar lo concerniente al fuero, López muestra dos cuestiones. La primera, la total asimilación entre la voz romana de la costumbre y su expresión jurídica en Espańa. La segunda, la distinción que hace de fuero en su sentido medieval y el que es más propio de su época. De tal modo, indica que si el fuero encierra a la costumbre y el fuero es derecho, la acepción de costumbre especificada no obedece a la de consuetudo, que ya es derecho de por sí para la mirada de López. Además, el fuero, dice López, en realidad es general, y justamente pone como ejemplo el caso del Fuero de las Leyes. Por ello, entiende que es impropio el uso de fuero también para el ámbito municipal. Sin embargo, explica que todavía en su tiempo permanece la indistinción terminológica.

\section{A MODO DE CONCLUSIÓN}

Algunos análisis ponen el énfasis en visiones doctrinarias sobre el derecho medieval. Nuestra propuesta, ha sido integrar el derecho dentro de su red de significaciones a partir del contexto de conflicto político en el que se desarrolla. Lo que postulamos es que la intencionalidad del texto alfonsí no propone un ordenamiento reglado sino una fagocitación de jurisdicciones medio de la subsunción de las formas jurídicas dentro del código legal. La apuesta de Alfonso X, nunca

derivación y la segunda acepción de Niermeyer es, justamente, soberanía (la primera es título imperial); majoriam entonces, en tanto que complemento directo de regis en la oración traducida está indicando esa majoria propia del rey que se cifra dentro de un círculo semántico que todo el tiempo está indicando una diferencia cualitativa de manera muy marcada (asociada, desde su concepción romana a los dioses). En Blaise las acepciones no difieren demasiado para majoriam, muestra la idea de impartir la máxima justicia, i. e. competencia jurisdiccional. Esto termina de cerrar, entonces, con la idea de "suprema jurisdicción" que parecería una redundancia en esa frase pero, precisamente, muestra la incapacidad léxica de la época de López para expresar de un modo contundente esa noción de soberanía que intenta plasmar desde una óptica jurisdiccional. En definitiva, traduzco lo que veo y siempre considero que acercarme a "lo literal" (como si el lenguaje tuviera una pura dimensión literal) es lo mejor, aunque implique que debamos explicar in extenso por qué vemos a nuestra propia traducción como inacabada. 
concretada, es la de un derecho homogeneizador y emanado del rey. Dentro de este corpus la consuetudo tiene la posibilidad de existir en la medida que emane de ese código regio. Dicho esto, además, hemos preferido una percepción que hace foco en la dimensión política de un conflicto que se cifra en el campo jurídico: los alcances y definición de la norma. De tal modo, hemos visto cómo el contexto incide en el texto y marca la agenda de una actividad cultural que expresa ese ambiente de lucha política.

El elemento ideológico que sustenta el procedimiento jurídico es el de "señor natural" que será el que marque, o intente demarcar, esa diferencia cualitativa que no se entiende por vía de la superioridad, sino de la majestad. Su contexto de actuación es el de la lógica de fidelidad, pero naturalizada, inapelable, no buscada ni consensuada y, lo más importante, indisoluble. Estos elementos integran un proceso de cambio dentro de los propios pliegues de la sociedad de ordines. De ese modo, la dialéctica propia de este proceso, lejos de encarnar la ruptura violenta del sistema de modo externo, se coloca dentro y lo subvierte al mismo tiempo que lo legitima, ubicándose siempre en un lugar de liminalidad y expresando tensiones irresolubles.

En el momento en que López introduce su voz en el texto, están ausentes ya aquellos elementos críticos que llevaron a la nobleza a la desnaturalización de I272. Como hemos podido comprobar, para López las instancias de conflicto tienen dos resoluciones. Primero, identifica no ya la idea de "señor natural" que aplica Alfonso, sino una verdadera jurisdicción suprema que refiere a los conceptos medievales de iurisdictio plenissima y plenitudo potestatis y que se definen bajo la voz de majestas. Segundo, las expresiones jurídicas disímiles a la ley pertenecen a un campo restringido de acción y son aceptadas en la medida que no compiten con aquella y se encuentren en su proceso de factura completamente asociadas a la figura del juez que es quien asegura el cumplimiento de la ley del rey. Además, hemos comprobado la completa juridización, es decir, su absoluta inscripción dentro del marco regulatorio del proceso jurídico que le da entidad y sustancia. De ese modo, lo que en Alfonso es un intentar definir para intervenir discursivamente en el contexto de lucha (podría decirse una retórica de combate), en López es un estado ya pasado que da muestras de la victoria del poder monárquico centralizado.

A partir de lo analizado en los diversos textos de Partidas del siglo XIII y la glosa de Gregorio López del siglo xvi vemos que la introducción de la costumbre dentro del sistema jurídico implica una serie de reglas que la acomodan a un marco de referencia dado. Este acomodamiento es el que las crea ya que permite que funcionen en el sentido de la costumbre como ius consuetudiarium. En rigor, 
no encontramos iurisdictiones perfectamente delimitadas, sino procesos de subsunción que la glosa de López no hace más que reafirmar con énfasis. Cuando plantea que nada puede ir en contra de la superioridad del rey y su jurisdicción, no se está refiriendo a un problema espacial ni de competencias legislativas entre iguales. Dicha glosa se refiere a la imposibilidad de violar un lugar de enunciación. El monarca no asegura un orden jurisdiccional de poderes relativamente independientes, sino que lo fagocita a la vez que lo crea, lo funda y lo recrea. ${ }^{34}$ Esto no puede ser el movimiento de un día. No puede alcanzarse con el simple hecho de enunciarlo. Hay que llevarlo a la práctica. Y porque existe la posibilidad de esta práctica es que se lo enuncia y luego será coyunturalmente explicado su éxito o fracaso.

Otro ejemplo claro que hemos podido ver es que en las relaciones entre posibilidades derogatorias ambos textos plantean la posibilidad de invalidar leyes y costumbres. Pero las formas en las que cada una debe proceder con respecto a la otra, reflejan una superioridad cualitativa, y ese es otro punto central. El hecho de resguardar la creación de leyes solo para una "jurisdicción”, con la capacidad derogatoria que esa ley tendrá sobre la costumbre, está mostrando una diferencia de cualidad y no de cantidad o de orden en la escala de iguales. El soberano expuesto en Siete Partidas, con especial énfasis en lo que las glosas de López muestran sobre el siglo XVI, es mucho más que el más alto ocupante de una escalera de jurisdicciones igualitarias. Este la atraviesa.

En definitiva, la introducción de la costumbre en el sistema jurídico alfonsí, su relación con la ley (cuestiones de derogación y competencia mutua), el lugar del monarca en la creación de normas, etc., nos habla de relaciones complejas ordenadas en torno a una autoridad en construcción que se expresa desde ese lugar político del conflicto de poderes. El lenguaje utilizado por el discurso medieval, por la evidente incapacidad de generar algo notoriamente nuevo, podría leerse como muestra de un intento de marcar una superioridad regia basada en el espacio jurisdiccional. Sin embargo, debemos atenernos al análisis que hemos expuesto ya para ver que en realidad hay marcas concretas en dicho discurso que implican diferencias cualitativas, que no están expuestas en idearios bien definidos sino (y he ahí su complejidad) en discursos en marcha.

${ }^{34}$ Este es el sentido de realizar una compilación normativa donde se proponga regular todo. A su vez, este es el espíritu constitucional tan buscado hasta el siglo xx en España y el sentido de un discurso jurídico que constituye conceptos políticos y que estuvo siempre presente en la historia peninsular. 
En referencia a la cuestión filológica hemos comprobado dos cosas. Primero, la redacción elegida por López es aquella que muestra la derrota política de Alfonso X: de allí, la presencia de ese segundo título que no existe previamente. Segundo, el título sobre la costumbre muestra una argumentación trunca, pobre y desarmada por parte del rey Sabio. Cosa que contradice el resto de su proceder discursivo (Cano Aguilar, 1996). En primer lugar, destacan las puras definiciones sin conexión entre leyes y la contradicción no exenta de circularidad, así como la parcialización de sus establecimientos. En contradicción, vemos un López muy presente en ese texto. Las "interrupciones textuales" que produce impiden verdaderamente una lectura fluida. En ese margen, forzado al centro por su dinámica de acción, se termina de producir la aclaración y la subsunción de esas expresiones jurídicas distintas a la ley, ya que López las coloca dentro de un marco específico de funcionamiento y, además, ocupa infinidad de glosas en reafirmar la definición de capacidades y la preparación técnica requerida para su factura.

En definitiva, hemos comprobado el uso del texto desde dos espacios concretos: sentido y forma. En su funcionamiento conjunto se produce el fenómeno de presencia continua. La obra Partidas del siglo XIII representa un poder y a la vez deja el espacio para su construcción como texto (teniendo en cuenta la diferenciación barthesiana) para ser llenado materialmente de la voz de otro: la glosa de López. Así, se comprueban dos operaciones pero con similares objetivos: una simbólica y otra concreta. La simbólica se cifra en la nueva puesta por escrito de la obra del rey Sabio. La concreta, en la intervención de López para construir un nuevo sentido dentro de las posibilidades que el marco elegido le proporcionaba.

\section{FUENTES}

Alfonso X el Sabio, I807: Las Siete Partidas del rey don Alfonso el Sabio, cotejadas con varios códices antiguos, Madrid.

Díaz de Montalvo, A. (ed.), I528: Alfonso X el Sabio, Las Siete Partidas del sabio Rey don Alfonso Nono por las cuales son deremidas et determinadas las questiones et pleytos que en España ocurren. Sabiamente sacadas de las leyes naturales, eclesiásticas et imperiales et de las fazañas, [...], Venecia. [Reproducción del Departamento de Reproducciones de la Biblioteca Nacional de España].

López, G. (ed.), I555: Alfonso X el Sabio, Las Siete Partidas del sabio rey don Alfonso el nono. Nuevamente glosadas por el licenciado Gregorio Lopez del Consejo Real de Indias de su Majestad, Salamanca. [Reproducción anastática del Boletín Oficial del Estado, 1974]. 
Mac Donald, R. (ed.), I990: Alfonso X el Sabio, I990: Especulo, Madison.

MS BM Add. 20.787 (British Museum, London).

MS HC 397/573 (Hispanic Society of America, New York).

MS X-I3I (Biblioteca Francisco de Zabálburu y Basabe, vitrina, Madrid).

ESTUDIOS

Arias Bonet, J., 1972: "Nota sobre el Códice neoyorkino de la Primera Partida", Anuario de Historia del Derecho Español, 42, pp. 753-756.

—, 1975: Alfonso X el Sabio, Primera Partida (Manuscrito Add. 20.787 del British Museum), Valladolid.

Bagge, S., 20Io: From Viking Stronghold to Christian Kingdom. State formation in Norway c. 900-1350, Copenhague.

Cano Aguilar, R., 1996: "La ilación sintáctica en el discurso alfonsî", Cahiers de linguistique médiévale, 2I, pp. 295-324.

Craddock, J., 198r: "La cronología de las obras legislativas de Alfonso X el Sabio", Anuario de Historia del Derecho Español, 51, pp. 365-418.

_ $1983:$ "Must the King Obey his Laws?", Florilegium Hispanicum: Medieval and Golden Age Studies Presented to Dorothy Clotelle Clarke, Geary, J. (ed.), Madison, pp. 7I-79.

Falhauber, Charles et al (comp.), 20II: BETA (Bibliografía Española de Textos Antiguos), Philobiblon, Berkeley. http://bancroft.berkeley.edu/philobiblon/index. html

García Gallo, A., I95I-I952: "El 'Libro de las Leyes' de Alfonso el Sabio. Del Espéculo a las Partidas", Anuario de historia del Derecho Español, 2I-22, pp. $345-528$.

—_, 1976: "Nuevas observaciones sobre la obra legislativa de Alfonso X", Anuario de historia del Derecho Español, 46, pp. 609-670.

—, 1984: "La obra legislativa de Alfonso X. Hechos e hipótesis", Anuario de historia del Derecho Español, 54, pp. 97-I6I.

Gumbrecht, H., 2004: Production of presence. What meaning cannot convey, Stanford.

Iglesia Ferreirós, A., I980: "Alfonso X el Sabio y su obra legislativa. Algunas reflexiones", Anuario de historia del Derecho Español, 50, pp. 53I-56I.

Lacomba, M., 2004: “Un discours historique marqué par la causalité: l'utilisation de la conjonction ca dans l'Estoria de España d'Alphonse X", Cahiers de linguistique hispanique médiévale, 27, pp. 7I-82. 
Lodares, J., 1996: "El mundo en palabras. Sobre las motivaciones del escritorio alfonsí en la definición, etimología, glosa e interpretación de voces", Cahiers de linguistique hispanique médiévale 2I, pp. I05-II8.

MacDonald, R., 1979: "The Editing of the Alfonsine Juridical Texts: Addendum”, La Corónica, 7/2, pp. II9-I2O.

Panateri, D., 20I5: "Sobre la datación de un manuscrito de Las Siete Partidas", Cahiers de linguistique hispanique médiévale, 85 (en prensa).

Rodríguez Velasco, J. D., 20I0: "La urgente presencia de Las Siete Partidas", La Corónica, 38/2, pp. 97-I34.

Rodríguez-Salgado, M., I988: The Changing face of Empire. Charles V, Philip II and Habsburg Authority, I55I-I559, Cambridge.

Rumeu de Armas, A., 1993-1994: "El jurista Gregorio López, Alcalde Mayor de Guadalupe, Consejero de Indias y Editor de Las Partidas", Anuario de Historia del Derecho Español, 63-64, pp. 345-450.

Wolf, A., I993-1994: "Los Iuria propria en Europa en el s. XIII", Glossae, 5-6, pp. $35-44$. 